$\xi_{p}$

\title{
An Investigation of Attached Biomass on Bio-Media using Scanning Electron Microscopy
}

\author{
Gasim Hayder ${ }^{*}$, Puniyarasen Perumulselum ${ }^{2}$ \\ 12 Sustainable Technology and Environmental Research Group, Institute of Energy Infrastructure, Department of Civil Engineering, \\ Universiti Tenaga Nasional, Jalan IKRAM-UNITEN, 43000 Kajang, Selangor, Malaysia \\ *Corresponding author E-mail: gasim@uniten.edu.my
}

\begin{abstract}
Biological film that attached to bio-media in attached growth wastewater treatment processes needs to be monitored and evaluated as it reflects the performance of the plant. Using Scanning Electron Microscopy (SEM) is an effective way for the examination of biofilms. Three different types of bio-media (bio-balls) were used to study the biofilm thickness using SEM. They are fin ball, spike ball and cage ball. Each type of bio-balls was cut into pieces since the size of SEM sample must be less than $25 \mathrm{~mm}$. The fin ball was cut into three pieces, the spike ball was cut into two pieces and the cage ball was cut into one piece. Only the non-identical parts from the bio-balls were chosen for SEM test. The cut pieces with biofilm growth were overnight dehydrated in laboratory oven before bring to the SEM for measuring and analysis of the thickness of biofilm growth. Based on average biofilm thickness of the cut pieces extracted from SEM test, cage ball and fin ball recorded the highest biofilm while spike ball has the lowest biofilm growth on it.
\end{abstract}

Keywords: Attached growth, wastewater treatment, Bio-media, Scanning electron microscopy.

\section{Introduction}

Biological wastewater treatment technologies have been gaining much attention in recent years. They offer low operational costs, provide easy handling, have comparatively less harmful effects on the corresponding environment, and they are efficient method [1]. In biological wastewater treatment, microorganisms will form biofilm to treat wastewater by consume organic matters and suspended particles in wastewater. In attached growth wastewater treatment plant the biofilm will be attached to bio-media that supports the growth of the biomass. Biofilm is an accumulation of microbial cells irreversibly associated with a surface enclosed in a matrix of bacterial self-generated extracellular polymeric substances (EPSs) [2]. Scanning electron microscope (SEM) is a useful technique to be used for biofilm analysis in wastewater treatment field. SEM produces image of sample by scanning the surface with the help of focused beam of electrons. From SEM, surface structure and morphology of a sample can be studied [3].

SEM is being widely used in wastewater treatment study for various purposes as well as in other fields such as monitoring the changes in microstructures and assessment of deformation [4]. In a study of photovoltaic wastewater treatment using electrocoagulation, SEM was used to characterize the solid products formed during electrocoagulation process. Structural features of the sludge generated by the electrochemical process were also analyzed in the same study using SEM. The SEM image showed that the surface of sample was presence with ultrafine particular structure [5]. Furthermore, SEM was used in study of $\mathrm{Pb} 2+$ removal by adsorption using treated granular activated carbon. Morphology of activated carbon after treatment was visualized by SEM to analyze the surface morphological changes. Clear demarcation in the surface of activated carbon was observed from SEM image [6]. In addi- tion, wastewater biofilm formation and structural components were studied using SEM. Significant increase in biofilm cell density was observed over the 144-h period with SEM [7]. In a study of dyes removal from textile wastewater, the SEM was used to investigate the physical characteristics of diatomite. The changes in diatomic structure were observed through SEM image [8]. On the other hand, SEM technique was used in SBR for the treatment of complex chemical wastewater. SEM was used to observe the morphology of biomass. The morphology of the biomass from SBR was heterogeneous with uneven surface texture having porous network internally. Well define mats of filamentous base was used to form the biofilm [9]. On top of that, SEM was used in a study of microbial fuel cells in aeration tank for wastewater treatment. The morphologies of biofilm developed in aeration tank were observed using SEM. From SEM images, it has been observed that biofilm attached to the carbon filament appeared to have a uniform morphology [10]. It can be concluded that, SEM is a very useful technique in biofilm study of wastewater treatment. SEM can be used to study the surface structure and morphology of biofilm developed in biological wastewater treatment. In this study, SEM has been chosen to measure the biofilm thickness on bio-balls because SEM allows higher resolution by the use of electron beams.

\section{Research Methodology}

Three different types of bio-balls were used to study the biofilm thickness. They are fin ball, spike ball and cage ball. Diameter of fin ball is $7.5 \mathrm{~cm}$ and it have $0.5 \mathrm{~cm}$ of fins around it. The diameter of the spike ball is $7.5 \mathrm{~cm}$. There were 14 spikes with the height of $1 \mathrm{~cm}$ on the surface of a spike ball. Besides that, the diameter of cage ball is $8 \mathrm{~cm}$ and it contained carries in it. 
The SEM analysis was the main experiment in this study as shown in Figure 1, therefore the test sample for each type of bio-balls was cut into pieces since the size of SEM sample must be less than $25 \mathrm{~mm}$. The fin ball was cut into three pieces, while the spike ball was cut into two pieces and the cage ball was cut into one piece. Only the non-identical parts from the bio-balls were chosen for SEM test.

An acrylic tank was fabricated to prepare samples for SEM test. The dimension of the tank is $1.6 \mathrm{~m}$ length, $0.5 \mathrm{~m}$ wide and $0.6 \mathrm{~m}$ height. A skeleton rack was also fabricated with acrylic to place the cut pieces of bio-balls as the sample preparation for SEM test. The rack is $0.2 \mathrm{~m}$ length, $0.2 \mathrm{~m}$ wide and $0.6 \mathrm{~m}$ height.

The source of the wastewater for the study was from the local sewage treatment plant. From the sewage treatment plant intake, the influent was pumped into the tank. Water pumps were installed inside the sewage treatment plant intake to pump the influent into the tank. The submersible pump has maximum flow rate up to $6000 \mathrm{~L} / \mathrm{H}$. Aeration was introduced to the tanks to provide oxygen for the microorganism in the tank. Air pump with pressure of $0.046 \mathrm{MPa}$ with output of $85 \mathrm{~L} / \mathrm{Min}$ were used for the aeration. The diffusers were positioned at bottom of the tanks to provide oxygen for the microorganism's growth and agitate the sludge continuously. The timer was set to operate the water pump for 1 minutes every one and half hours. The timer was used to maintain the 6 hours of HRT.

Growth on the cut pieces of bio-balls were sent to material characterization laboratory for SEM analysis as the thickness of biofilm growth was measured. The cut pieces with biofilm growth were carefully dehydrated at $30{ }^{\circ} \mathrm{C}$ for $24 \mathrm{~h}$ in hot air oven and the samples were coated with gold before brought to the lab for SEM analysis [9].

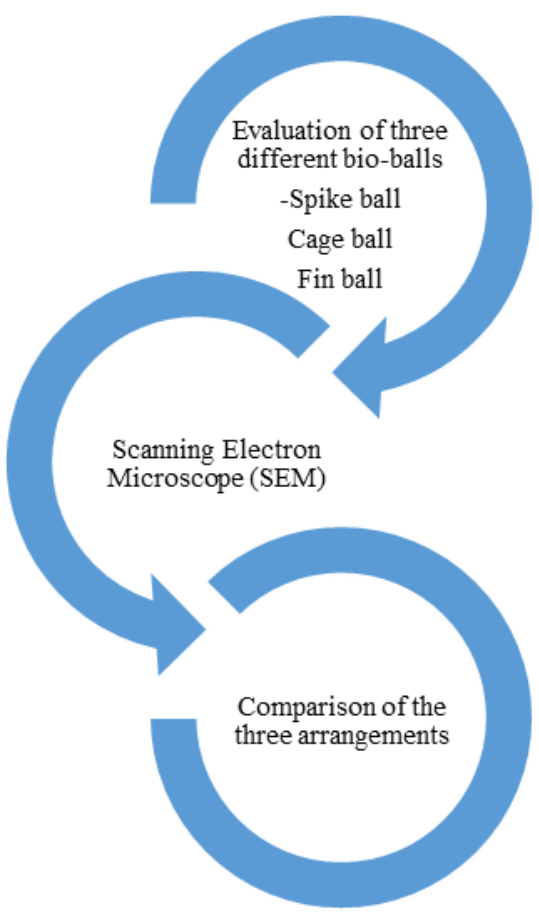

Fig. 1: The SEM test

\section{Results and Discussion}

The thickness of biofilm growth was measured by using SEM and Figure 2 shows the parts chosen for SEM test from fin ball. Table 1 shows the thickness of biofilm growth of fin ball cut pieces obtain from SEM test. Figure 3 to 5 show the image of fin ball cut pieces with biofilm growth captured from SEM test. Among the three cut pieces, cut piece F3 recorded the highest biofilm thickness which is $170 \mu \mathrm{m}$. Cut piece F2 recorded the lowest biofilm thickness of $54 \mu \mathrm{m}$ while cut piece F1 recorded biofilm thickness of $75 \mu \mathrm{m}$. Cut piece F3 has the largest surface area followed by F1 and F2. Surface area will be the reason for the differences in biofilm growth. Cut piece F2 recorded the lowest biofilm because of the smaller surface area and also the cut piece has the hole which will be the path of flow. Pressure difference because of the hole will disturb the biofilm growth. The biofilm growth on fin ball has an average biofilm thickness of $99.67 \mu \mathrm{m}$ which is the highest biofilm thickness recorded compared to spike ball and cage ball cut pieces.

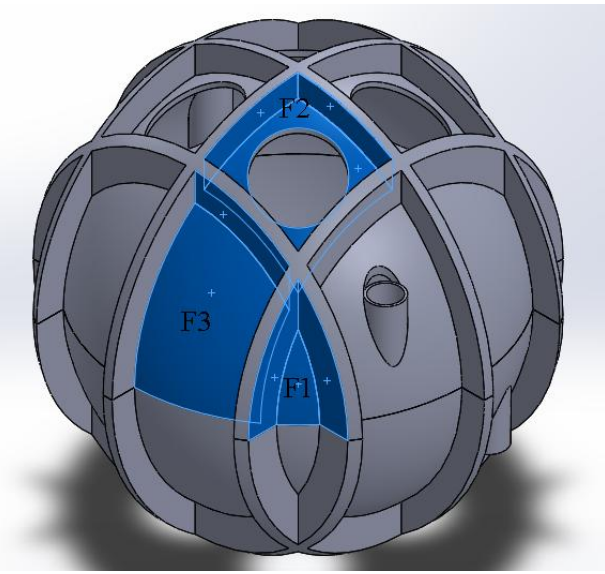

Fig. 2: Parts chosen from Fin Ball

Table 1: Fin Ball SEM Results

\begin{tabular}{|l|l|}
\hline Name & Biofilm Thickness $(\mu \mathrm{m})$ \\
\hline F1 & 75 \\
\hline F2 & 54 \\
\hline F3 & 170 \\
\hline
\end{tabular}

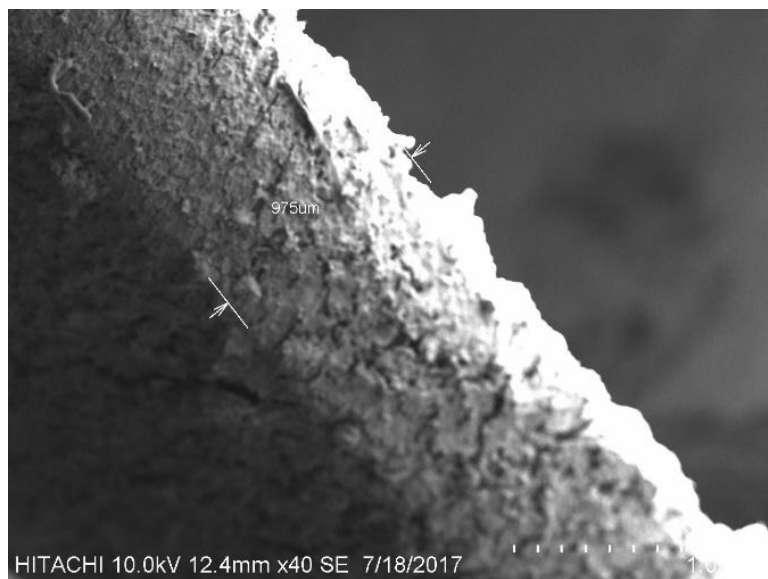

Fig. 3: SEM image of F1

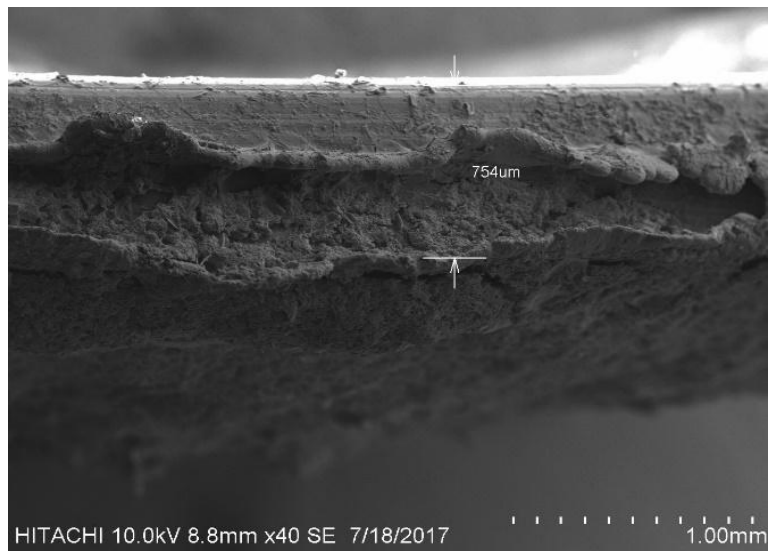

Fig. 4: SEM image of F2 


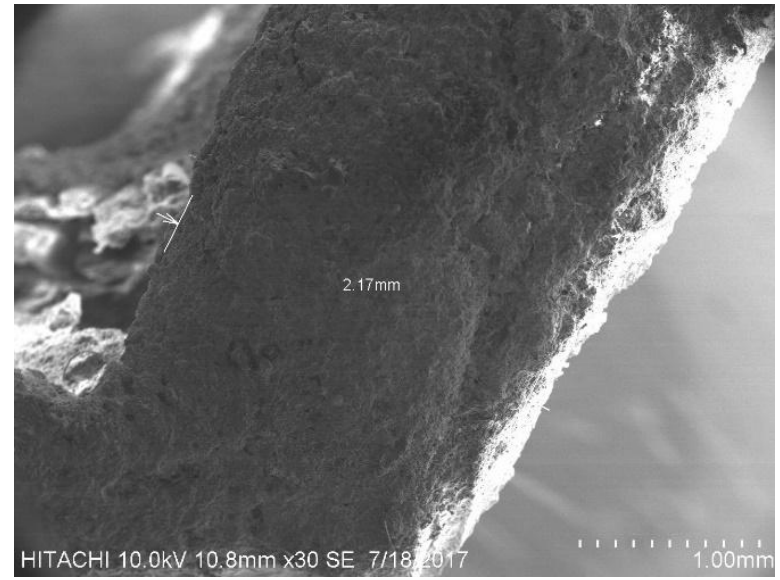

Fig. 5: SEM image of F3

Figure 6 shows the parts chosen for SEM test from spike ball. Table 2 shows the thickness of biofilm growth of spike ball cut pieces obtain from SEM test. Figure 7 and 8 show the image of spike ball cut pieces with biofilm growth captured from SEM test. Cut piece S1 recorded the highest biofilm thickness of $46 \mu \mathrm{m}$ and $20 \mu \mathrm{m}$ thick biofilm growth has been observed at cut piece S2. Same like cut piece F2, cut piece S2 also has the hole which will create a pressure difference and disturbs the biofilm growth. Only $20 \mu \mathrm{m}$ of biofilm was recorded from cut piece S2. The biofilm growth on spike ball has an average biofilm thickness of $66 \mu \mathrm{m}$ which less than average growth on fin ball.

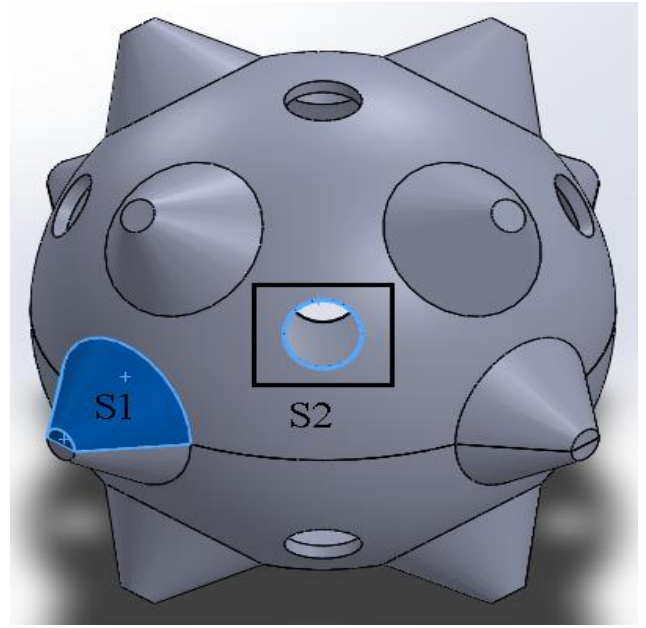

Fig. 6: Parts chosen from Fin Ball

Table 2: Spike Ball SEM Results

\begin{tabular}{|l|l|}
\hline Name & Biofilm Thickness $(\mu \mathrm{m})$ \\
\hline S1 & 46 \\
\hline S2 & 20 \\
\hline
\end{tabular}

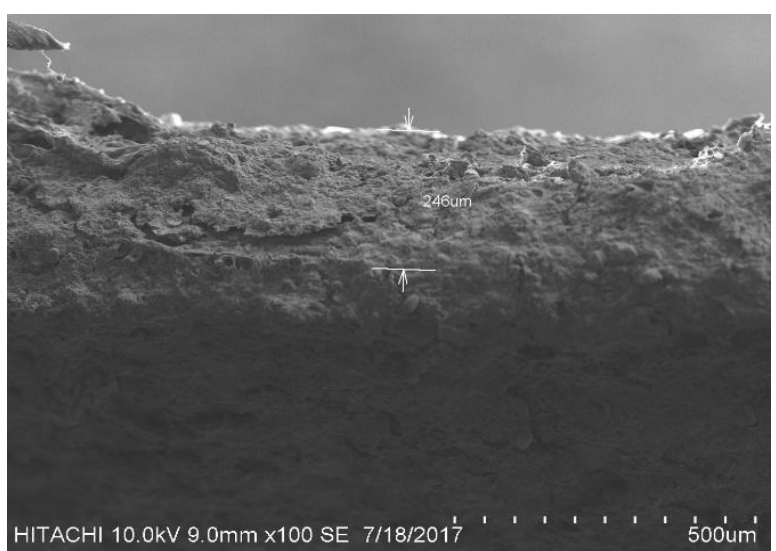

Fig. 7: SEM image of S1

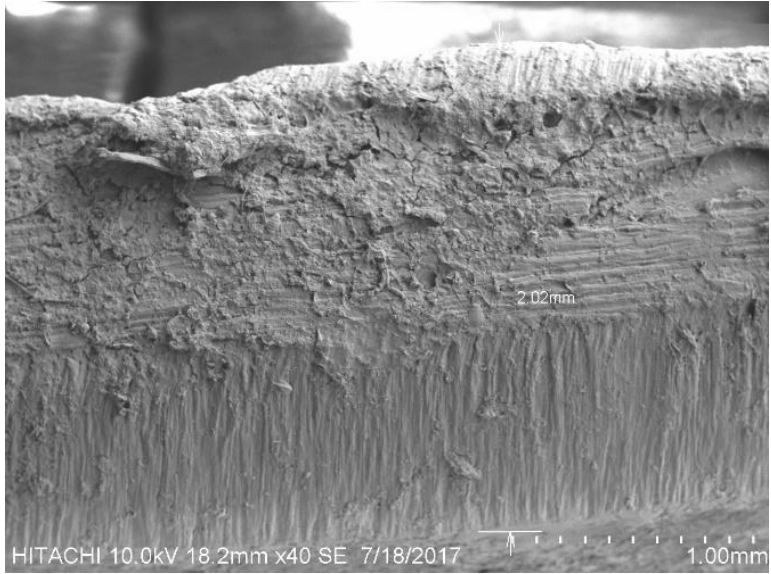

Fig. 8: SEM image of S2

Figure 9 shows the parts chosen for SEM test from cage ball. Table 3 shows the thickness of biofilm growth of cage ball cut piece obtains from SEM test. Figure 10 shows the image of cage ball cut piece with biofilm growth captured from SEM test. Cut piece $\mathrm{C} 1$ recorded $91.3 \mu \mathrm{m}$ of biofilm thickness. The thickness almost in the same range of fin ball cut pieces.

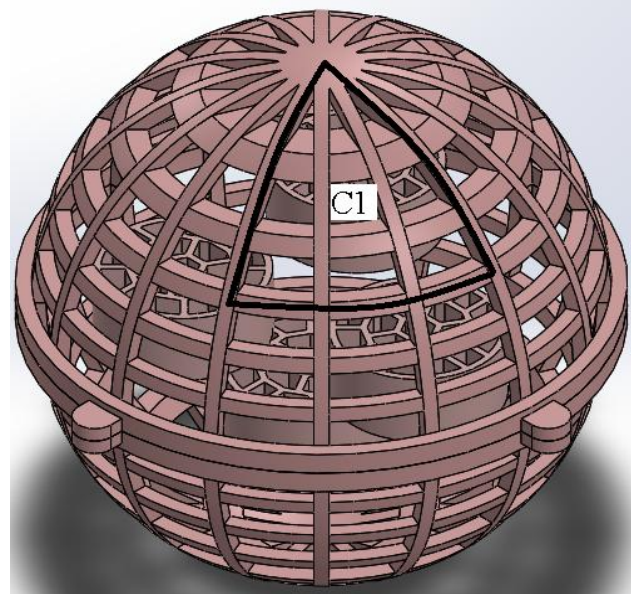

Fig. 9: Parts chosen from Spike Ball

Table 3: Cage Ball SEM Results

\begin{tabular}{|l|l|}
\hline Name & Biofilm Thickness $(\mu \mathrm{m})$ \\
\hline $\mathrm{C} 1$ & 91.3 \\
\hline
\end{tabular}

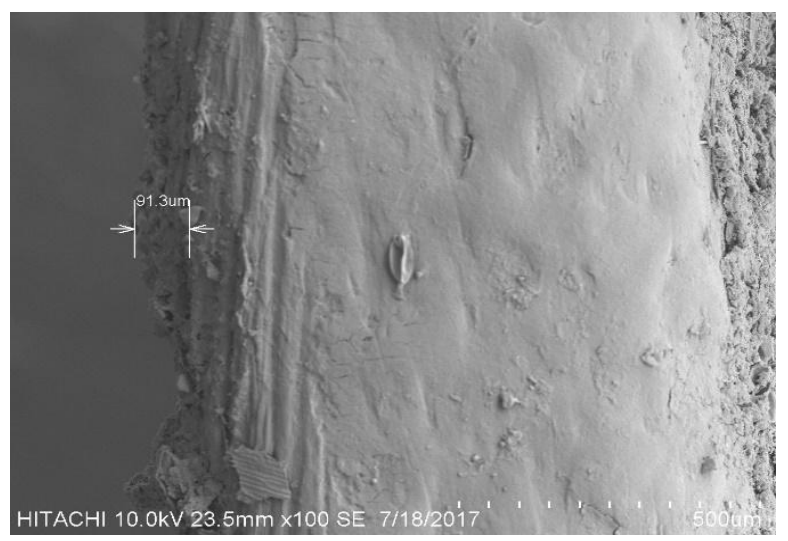

Fig. 10: SEM image of $\mathrm{C} 1$

\section{Conclusion}

The SEM test was carried out to obtain the thickness of biofilm growth on bio-balls. The thicker the biofilm growth will improve the wastewater treatment process. Therefore, from this test, the best type of bio-ball can be identified in term of biofilm growth. 
There were three types of bio-balls used for this test. They are fin ball, spike ball and cage ball. Fin ball were cut into three pieces for SEM test and kept in acrylic skeleton. Spike ball were cut into two pieces and cage ball were cut into one piece for SEM test. All three types of bio-balls are currently used in wastewater treatment plants, however, there is always a need to compare the shape and design of the bio-media and the surface area that they could provide for attachment of the biofilm as well as the actual developed biofilm thickness. Based on average biofilm thickness of the cut pieces extracted from SEM test, cage ball and fin ball recorded the highest biofilm while spike ball has the lowest biofilm growth on it. This work can further be supported by long term monitoring of the biofilm.

\section{Acknowledgement}

The authors would like to acknowledge the Ministry of Higher Education of Malaysian for the financial support under Fundamental Research Grant Scheme (FRGS) with reference number 20160109FRGS.

\section{References}

[1] Gasim, H., Megat, A. R. M. M. A., \& Shamsul, R. M. K. (2015) Treatment of petroleum refinery wastewater using extended aeration activated sludge. In International Journal of Engineering Research in Africa (Vol. 13, pp. 1-7). Trans Tech Publications.

[2] Sehar, S., \& Naz, I. (2016). Role of the biofilms in wastewater treatment. In Microbial Biofilms-Importance and Applications. InTech.

[3] Diao, H. F., Li, X. Y., Gu, J. D., Shi, H. C., \& Xie, Z. M. (2004). Electron microscopic investigation of the bactericidal action of electrochemical disinfection in comparison with chlorination, ozonation and Fenton reaction. Process biochemistry, 39(11), 14211426.

[4] Bayarassou, M., Zidani, M., \& Farh, H. (2018). Microstructural Evolution and Mechanical Properties during Homogenization and Ageing Treatment of Al-Mg-Si Alloy Wire Cold Drawn. In International Journal of Engineering Research in Africa (Vol. 36, pp. 6068). Trans Tech Publications

[5] Drouiche, N., Aoudj, S., Hecini, M., Ghaffour, N., Lounici, H., \& Mameri, N. (2009). Study on the treatment of photovoltaic wastewater using electrocoagulation: Fluoride removal with aluminium electrodes - Characteristics of products. Journal of Hazardous Materials, 169(1-3), 65-69.

[6] Goel, J., Kadirvelu, K., Rajagopal, C., \& Garg, V. K. (2005). Removal of lead (II) by adsorption using treated granular activated carbon: batch and column studies. Journal of hazardous materials, 125(1-3), 211-220.

[7] Eighmy, T. T., Maratea, D., \& Bishop, P. L. (1983). Electron microscopic examination of wastewater biofilm formation and structural components. Applied and environmental microbiology, 45(6), 1921-1931.

[8] Al-Ghouti, M. A., Khraisheh, M. A. M., Allen, S. J., \& Ahmad, M. N. (2003). The removal of dyes from textile wastewater: a study of the physical characteristics and adsorption mechanisms of diatomaceous earth. Journal of Environmental Management, 69(3), 229-238.

[9] Mohan, S. V., Rao, N. C., Prasad, K. K., Madhavi, B. T. V., \& Sharma, P. N. (2005). Treatment of complex chemical wastewater in a sequencing batch reactor (SBR) with an aerobic suspended growth configuration. Process Biochemistry, 40(5), 1501-1508

[10] Cha, J., Choi, S., Yu, H., Kim, H., \& Kim, C. (2010). Directly applicable microbial fuel cells in aeration tank for wastewater treatment. Bioelectrochemistry, 78(1), 72-79. 